\title{
EXTRAÇÃO MINERAL DE QUARTZITO E SUA APLICABILIDADE NA CONSTRUÇÃO CIVIL NA CIDADE DE VÁRZEA - PB
}

\author{
D. A. SANTOS ${ }^{1}$, M. T. GURGEL ${ }^{2}$, A. F. MOTA ${ }^{3}$ e F. I. G. PAIVA ${ }^{4}$ \\ Universidade Federal Rural do Semi-árido, Mossoró-RN \\ dennys.slash@gmail.com ${ }^{1}$, marcelo.tavares@ufersa.edu.br ${ }^{2}$, andygley_fm@hotmail.com ${ }^{3}$, italo- \\ gp@hotmail.com ${ }^{4}$
}

Artigo submetido em setembro/2013 e aceito em março/2014

DOI: 10.15628/holos.2014.1675

\section{RESUMO}

A exploração mineral no Brasil vem se intensificando nos últimos anos e um dos setores que solicitam esse aumento de produção é a construção civil, dentre as quais se podem citar o uso de rochas em caráter ornamental. O quartzito é um exemplo bem claro dessas rochas. A cidade de Várzea - PB tem um grande respaldo em âmbito nacional na produção (extração e beneficiamento primário) desse mineral e foi tomada como ambiente de estudo. O trabalho consiste em um estudo sobre o ciclo padrão de produção do quartzito e seus impactos ambientais na cidade de Várzea - PB, além de uma avaliação sobre a resistência desse material. Para isso foi feito um levantamento em campo dos efeitos locais, no período de outubro a novembro de 2011, e também uma comparação da velocidade de propagação de ondas ultrassônicas entre o quartzito e o concreto de traço específico utilizado na construção civil. As práticas extrativistas e de beneficiamento adotadas na cidade de Várzea - PB oferecem certo risco ao meio ambiente. 0 quartzito é um excelente material de âmbito ornamental, e de grande resistência podendo ser aplicável estruturalmente na construção civil.

PALAVRAS-CHAVE: Extração mineral, Impacto ambiental, Aplicações na construção civil.

\section{QUARTZITO MINERAL EXTRACTION AND ITS APPLICABILITY IN CONSTRUCTION IN THE CITY OF VÁRZEA - PB}

\section{ABSTRACT}

Mineral exploration in Brazil has intensified in recent years and one of the sectors requesting this increase in production is the construction industry, among which we can mention the use of rocks in ornamental character. The quartzite is a clear example of these rocks. The city of Várzea - PB has great support in national production (extraction and primary processing) and this mineral was taken as study environment. The work consists of a study on the standard cycle of production of quartzite and its environmental impacts in the city of Várzea - PB, and an
\end{abstract}

assessment of the strength of materials. For this was made a field survey of local effects in the period OctoberNovember 2011, and also a comparison of the speed of propagation of ultrasonic waves between the quartzite and concrete specific trait used in construction. The extraction and processing practices adopted in the city of Floodplains - PB offer some risk to the environment. The quartzite is an excellent material within ornamental, and high strength can be applied in structural construction.

KEYWORDS: Mining, Environmental impact, Applications in construction. 


\section{INTRODUÇÃO}

A extração de rocha e mineral é uma das principais fontes de obtenção de insumos essenciais para a vida do homem, apresentando-se como atividade intrinsecamente ligada ao comportamento e aos anseios da humanidade. Isso a torna necessária e indispensável para o equilíbrio do avanço tecnológico, econômico ou social, pois é responsável pela garantia do combustível que move o sistema no qual a sociedade é organizada. $\mathrm{O}$ uso de recurso natural não é nenhuma novidade, nem mesmo algo inapropriado, já que essa é sua finalidade e assim é feito desde os primórdios da história da humanidade.

Surge um problema quando foge o controle sobre o ritmo e intensidade de exploração dos recursos naturais. A partir de certo momento, segundo Freitas (2009) principalmente após a Primeira Revolução Industrial, a sociedade passa a explorar mais os recursos existentes, chegando ao ponto de extrair mais do que necessita sem se preocupar com a quantidade existente do material. $O$ exercício da atividade extrativista de minerais e rochas provoca danos irreversíveis ao meio ambiente. Essa ação pode proporcionar efeitos em grande escala, uma vez que a matéria rochosa é extraída do solo e subsolo, ao passo que atinge um raio superficial no exercício dos seus métodos de exploração mineradora.

A extração mineral no Brasil é historicamente favorecida pela sua formação geológica e pela extensão territorial, tendo inúmeros minerais de interesse econômico no rol de minérios extraídos provenientes de embasamento cristalino e bacias sedimentares. Segundo Neves\& Silva (2007) a exploração é classificada em classes, sejam metálicas, não metálicas, gemas e diamantes e energéticos, dentre as quais cerca de $90 \%$ das minas existentes no país se dedicavam à exploração de minerais não metálicos. Desse total, aproximadamente $80 \%$ foram de minas voltadas aos minerais usados na construção civil, como areias, argilas, rochas britadas e ornamentais. Esse grande conjunto merece destaque pelo aquecimento da construção civil que a cada ano intensifica-se no Brasil.

As rochas ornamentais ganham ênfase pela demanda existente por novos tipos de rochas exóticas quartzíticas e calciossilicáticas para uso na construção civil, por terem várias tonalidades e texturas. Essas rochas requerem atenção especial quanto à sua extração e beneficiamento devido a sua importância e valor ao mercado imobiliário. É importante se utilizar técnicas que visem o melhor aproveitamento do material, o que é ignorado na maioria dos casos, onde não existe sequer o menor estudo de impacto ambiental da atividade no ambiente de extração.

De acordo com Parahyba et al (2009) a grande maioria da produção nacional de rochas ornamentais estão concentrada nos estados do Espírito Santo e Minas Gerais, na região Sudeste do Brasil. Apesar de não deter a maior produção, na região do Semiárido verifica-se a maior diversidade geológica do país, ou seja, maior diversidade de elementos e processos geológicos. Dentre os estados Nordestinos, destacam-se a Bahia, o Ceará e Paraíba como os três maiores produtores.

Nesse contexto, de respaldo de rochas quartzíticas e calciossilicáticas, uma cidade no interior da Paraíba vem se destacando há alguns anos pela sua produção de Quartzito. A cidade de Várzea contribui significativamente em âmbito nacional nessa atividade, desenvolvendo e aprimorando ao longo do tempo a atividade de extração e beneficiamento da rocha que tem como principais produtos 
finais ladrilhos, mosaicos para pisos etc. Segue então, um estudo sobre os principais impactos causados pela atividade extrativista da rocha quartzítica na cidade de Várzea - PB, acompanhada de uma análise da qualidade do produto em si e sua aplicabilidade na construção civil.

O quartzito é uma rocha ornamental metamórfica, apresenta uma tendência a ser coesa, com estrutura cristalina densa e organizada de modo que a força do cimento entre as partículas propicia uma resistência interna bastante alta. Com isso seria possível avaliar como uma estrutura de rocha metamórfica pode proporcionar boas características favoráveis para o uso como rocha ornamental bem como as possibilidades e vantagens de poder usá-la, eventualmente, como componente estrutural de obra.

Diante disso, o presente trabalho objetivou avaliar os efeitos da exploração de do quartzito sobre o ambiente e suas propriedades estruturais para a construção civil na cidade de Várzea - PB.

\section{METODOLOGIA}

\subsection{Caracterização da pesquisa}

A presente pesquisa caracteriza-se pela coleta de dados em campo sobre a exploração do quartzito na cidade de Várzea no estado da Paraíba. A jazida do município de Várzea, da qual são extraídos os recursos minerais estudados, é uma grande bacia que se estende do Rio Grande do Norte até à Paraíba, cuja dimensão real ainda é desconhecida. O município de Várzea está inserido no Polígono das Secas. Possui clima Bsh-Tropical, quente, seco, semiárido com chuvas de verão. Em regiões bioclimáticas o município da Várzea enquadra-se no bioclima $2 b$-Sub-desértico, quente, de tendência tropical, com 9 a 11 meses secos. A pluviometria média anual é de 600 à $800 \mathrm{~mm}$ e de distribuição irregular. A vegetação é do tipo Caatinga-Seridó e a temperatura média anual é de 28C. Está inserido na formação geológica Seridó e jucurutú.

2.2 Avaliação dos impactos ambientais dos processos de extração e beneficiamento do quartzito em Várzea - PB

Para a avaliação de impactos ambientais deste processo, o levantamento de dados foi realizado junto à classe trabalhista da cidade de Várzea que se dedica, quase que por unanimidade, à extração de quartzito. Nessa etapa foi feita uma visita técnica no dia 22 de outubro de 2011 à cidade de Várzea para coleta de dados junto aos exploradores e beneficiadores do quartzito, com aplicação de um questionário específico para cada setor (em anexo) contendo as diretrizes dos principais pontos necessários para que fossem alcançados os objetivos.

Existe cerca de 80 jazidas na área de extração, sendo aproximadamente 30 delas situadas na cidade de Várzea - PB. Desse total, a entrevista foi realizada com $20 \%$ dos proprietários/produtores das jazidas de quartzito. Existem 10 indústrias beneficiadoras da rocha, das quais foi feita entrevista com $20 \%$ dos proprietários/beneficiadores. Além disso, foram obtidas (coletadas e preparadas) amostras da rocha para a caracterização tecnológica no Laboratório de Materiais de Construção Civil - UFERSA.

Foram propostas discussões e colocadas indagações sobre a exploração e beneficiamento da rocha. Os resultados obtidos em campo foram relacionados com a fundamentação teórica. 
2.3 Análise das propriedades do quartzito e aplicações ornamentais e estruturais na construção civil

Para caracterização das aplicações ornamentais possíveis para o Quartzito, foi feita uma relação entre as propriedades da rocha e os esforços característicos nos prováveis ambientes de utilização, ou seja, uma caracterização teórica da rocha com base nas literaturas consultadas.

Por sua vez, a caracterização do Quartzito com relação a sua aptidão para ser utilizado estruturalmente foi feito através do ensaio de ultrassom no Laboratório de Construções Rurais da Universidade Federal Rural do Semi-árido (UFERSA). Como recomenda Bauer (2008), de posse de corpos-de-prova de concreto de traço e resistência à compressão conhecidos e de corpos-de-prova de quartzito realizou-se o exame que consiste em mensurar a velocidade de propagação de ondas sônicas através dos mesmos, assim como a taxa de dispersão das mesmas.

Ao saber a velocidade de propagação de uma onda padrão $(54 \mathrm{kHz})$ em ambos os tipos de corpos-de-prova, foi feita a caracterização, partindo do princípio de que o concreto é o material mais utilizado por ter boas características resistivas a esforços de compressão. A competência do Quartzito para esse tipo de resistência pode ser estimada quando sua velocidade de propagação de ondas é comparada à do concreto. Esses parâmetros, por conseguinte, são estimadas observando a capacidade de transmissão de ondas sonoras.

Para aferir a velocidade de propagação dos materiais mencionados acima foi utilizado o aparelho de ultrassom disponível no laboratório supracitado na UFERSA (Figura 1). Também foi utilizado um paquímetro digital para medir, à 0,01 mm, o comprimento dos corpos-de-prova.

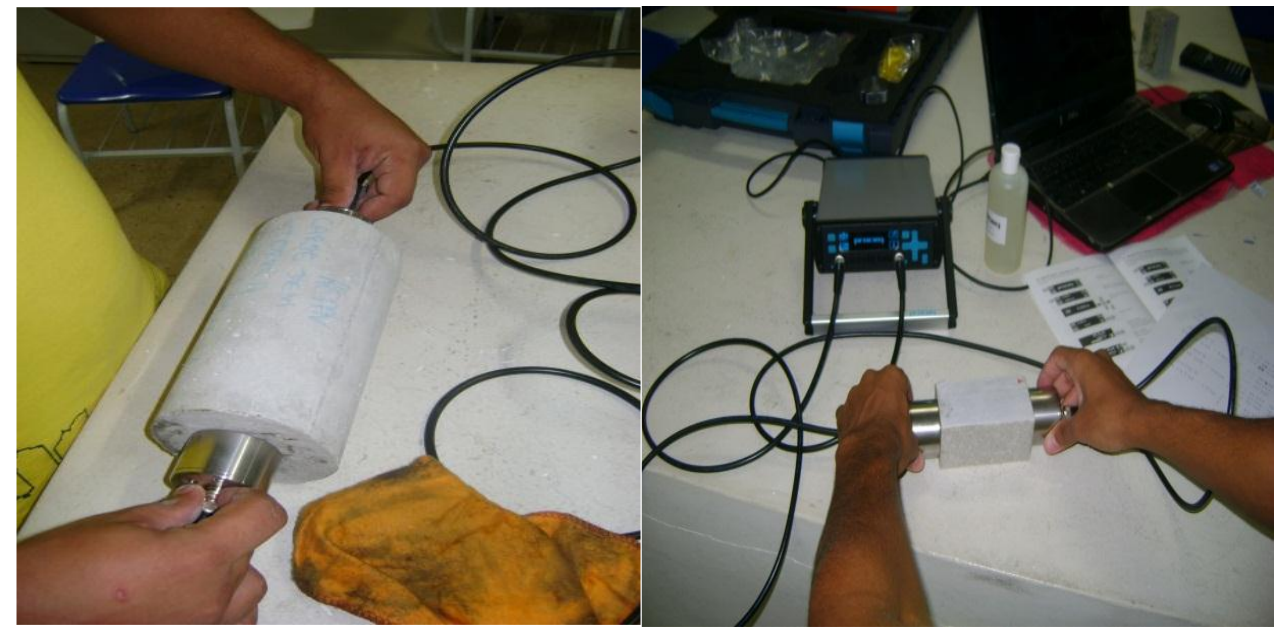

Figura 1: Ensaio de ultrassom: a) Corpo-de-prova de concreto (esquerda); b) Corpo-de-prova de quartzito (direita).

De base em Bottega (2010), foram utilizados três corpos-de-prova de concreto cilíndricos cujas dimensões são $10 \times 20 \mathrm{~cm}$, diâmetro e altura, respectivamente e quatro corpos-de-prova de quartzito com dimensões de $5 \times 5 \times 10 \mathrm{~cm}$, largura, comprimento e altura, respectivamente. 0 ensaio foi realizando com base nas normas NBR 8802 da ABNT e N 1594 da PETROBRÁS. O concreto utilizado tem o traço de 1:2:2,5, que corresponde respectivamente a cimento, areia e brita, servindo como padrão para esse estudo.

Os resultados das velocidades foram expressos em gráficos gerados no software Punditlink em função da amplitude e do tempo necessário para a propagação no material. 


\section{RESULTADOS E DISCUSSÃO}

Os resultados apresentados a seguir são baseados nas informações obtidas com os questionários direcionados ao campo de extração e a indústria de beneficiamento, que servem de base para explicar todo o procedimento de exploração do quartzito na cidade de Várzea-PB.

\subsection{Processo de produção e Avaliação ambiental}

O processo de produção do quartzito na cidade de Várzea - PB resume-se em dois processos distintos, porém intimamente relacionados: extração e beneficiamento. $O$ processo de extração trata-se da obtenção da rocha diretamente da natureza, da forma como fora formado, enquanto que o beneficiamento remete ao conjunto de processos que conferem ao material as propriedades necessárias para seu uso.

A extração de quartzitos na Paraíba ocorre longe dos grandes centros urbanos, em pequenos municípios, situados no interior do Estado, em áreas constituídas de vegetação típica da caatinga, com reduzido índice pluviométrico e com baixo potencial hídrico. (SOUZA et al., 2001). 0 fluxograma abaixo ilustra as etapas pelas quais o quartzito passa na mineração na cidade de Várzea/PB (Figura 2).

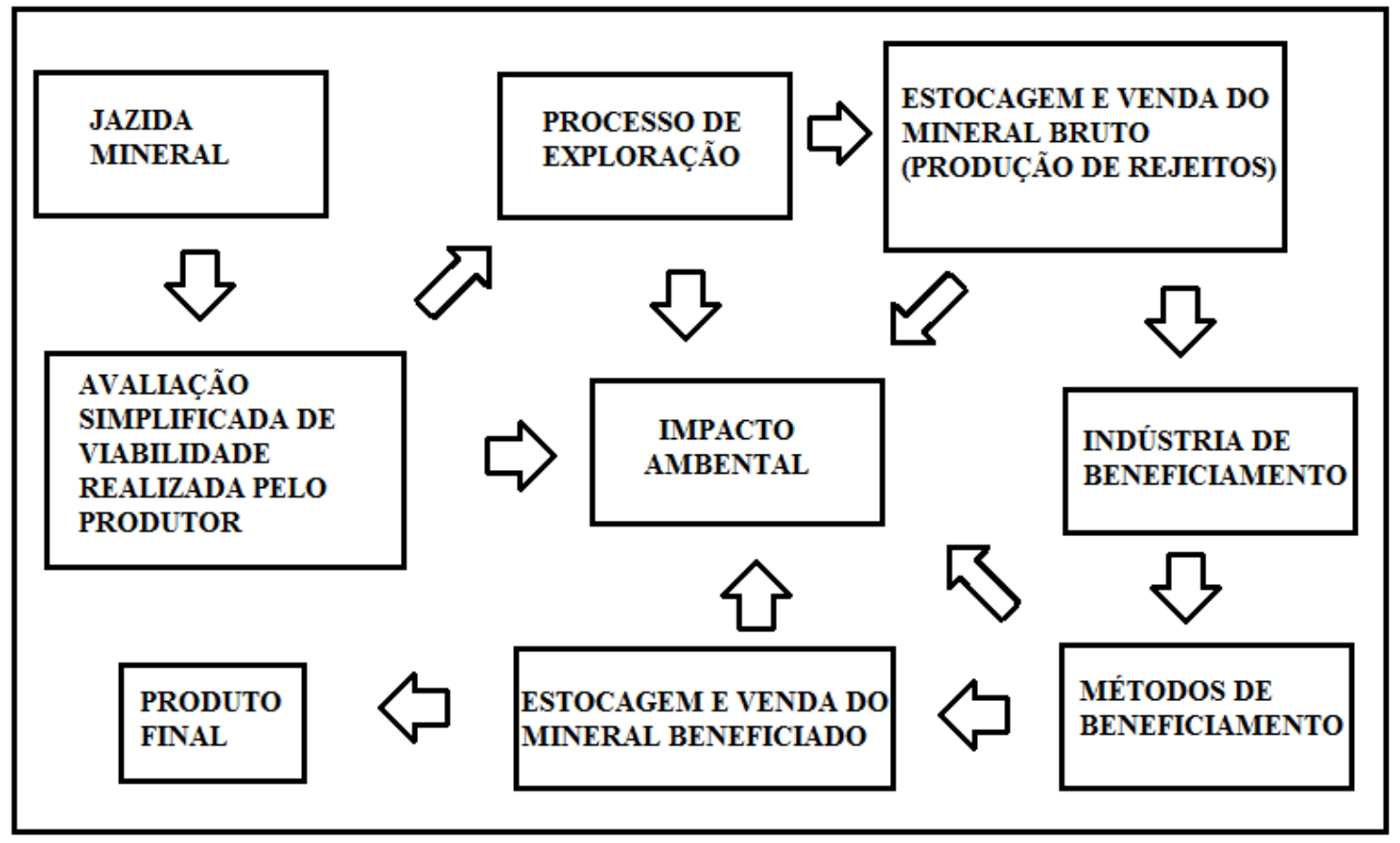

Figura 2: Fluxograma das etapas de produção do quartzito.

Constatou-se que a extração inicia-se com uma estimativa de viabilidade da jazida por cada produtor/proprietário com base na sua experiência, pois não existem recursos tecnológicos para realização de estudos prévios para mensurar a quantidade de rocha que contém em uma determinada área.

Segundo o relato dos trabalhadores, o processo é simples, inicia-se com abertura de furos na parte inferior da rocha de acordo com os limites desejados para o tamanho do bloco, com uso de um compressor de ar em um processo conhecido popularmente como raiação. Neles são inseridos os explosivos que provocam um choque mecânico na rocha, obtendo os blocos e, em 
seguida, as placas por desmonte artesanal, que são frações planas e de pouca espessura graças à boa clivagem existente na rocha.

Além da poluição sonora gerada pelas explosões, a extração provoca uma série de impactos, como alteração da paisagem pela remoção do solo e da vegetação. Em consequência disso, foi possível observar a migração da macrofauna nas áreas mineradas, e a eliminação parcial da microfauna. Além dos riscos de erosão e desertificação.

Os impactos ambientais mais negativos, provocados por esse tipo lavra, foram observados sobre o solo, refletidos na modificação da paisagem, mediante a remoção indiscriminada da vegetação, e a disposição inadequada de um grande volume de rejeitos, concordando com Souza et al. (2001).

Dos resíduos sólidos inorgânicos gerados quase a totalidade são de fragmentos do quartzito que se desprendem durante a explosão e que são descartados na confecção e esquadrejamento das lajes. A parcela restante de resíduos é composta por pequenos cristais formados pela fragmentação da rocha em solo, como os seixos rolados (pedras que sofreram intemperismo e se encontram em proporções reduzidas - presentes em grande quantidade na região), bem como o próprio saprólito (Figura 3).

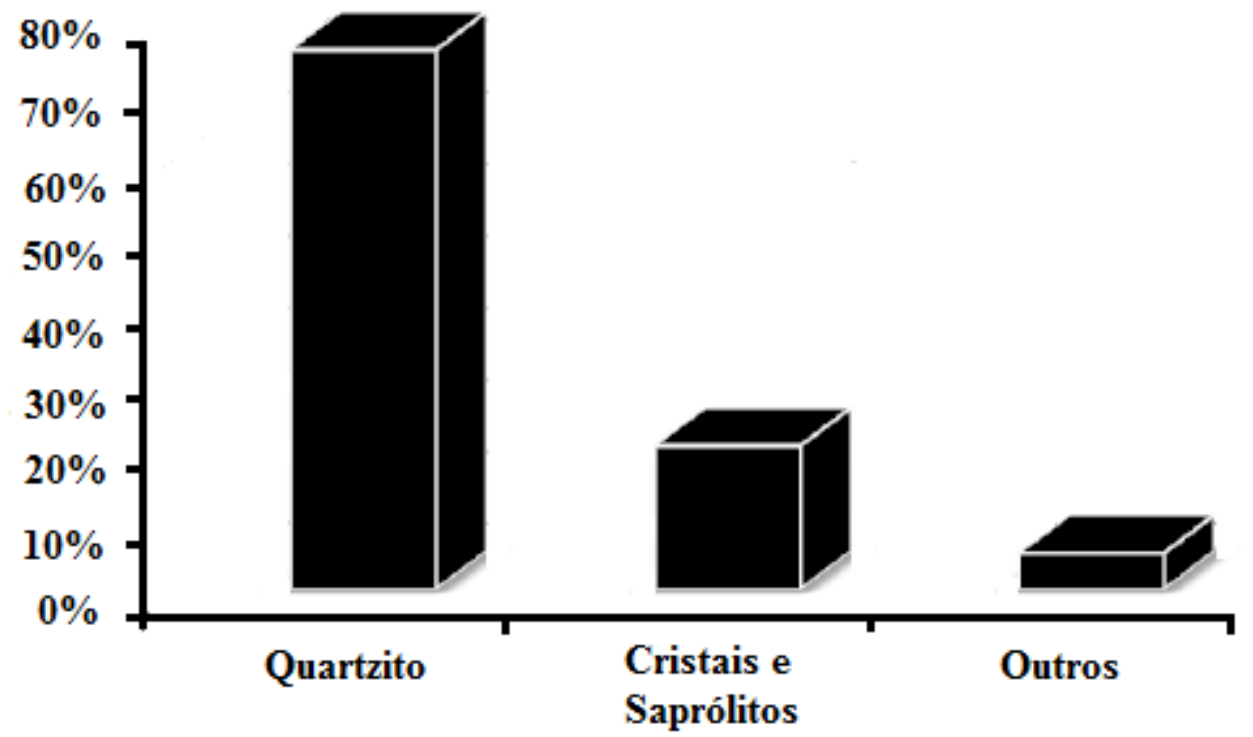

Figura 3: Gráfico da composição dos resíduos sólidos.

Para diminuir percentualmente a quantidade de resíduo sólido gerado está associado à tecnologia. A cada dia que passa pesquisadores, juntamente com órgãos ambientais, inserem no mercado máquinas de corte mais precisas que extraem apenas blocos, cujos formatos variam de acordo com o equipamento. Com isso, segundo o presidente do sindicato de produtores, a quantidade de resíduos gerados seria reduzida até $70 \%$.

$\mathrm{O}$ beneficiamento refere-se essencialmente ao conjunto de processos realizados no material rochoso com o intuito de que ele incorpore aspectos estéticos artificiais que lhe agreguem valorização monetária. Isso porque ao final estarão mais atraentes visualmente, bem como a garantia de presença de bons aspectos físicos. No decorrer do beneficiamento são detectados e excluídos os 
blocos com defeitos, garantindo que apenas placas de alta qualidade (estética e físico-química) sejam comercializadas.

O quartzito bruto chega até as indústrias de beneficiamento (serrarias) sob a forma de lajes, como fora mencionado, para passar pelo processo de esquadrejamento mecânico. Esse procedimento é realizado para dar às lajes formatos de acordo com os tipos de material de revestimento desejado. Consiste em uma serragem em teares, onde as lâminas são diamantadas e de raio pequeno chegando, no máximo, a atingir $15 \mathrm{~cm}$.

Para que o corte seja realizado com precisão e perfeição utiliza-se água como fluido esfriante que preserva a integridade da lâmina ao passo que garante um bom corte. Uma grande quantidade de água é requerida constantemente para garantir as boas condições de trabalho, por este motivo os órgãos ambientais instituíram a obrigatoriedade de reutilização da água por meio de tanques de decantação, reduzindo assim o desperdício exorbitante.

A atividade também produz uma grande quantidade de poeira (resíduo sólido granular), que polui, ainda que em baixa escala, o perímetro urbano próxima ao setor de serrarias.

Contudo o impacto ambiental que mais castiga é a geração de resíduos sólidos, tanto nas indústrias como nas jazidas. A cada dia que passa pilhas e mais pilhas vão se aglomerando nas proximidades das jazidas, bem como das serrarias. Pensando nisso, foi permitida a alocação desses resíduos em uma área de acidente topográfico visando fazer um aterro com o material descartado ao passo que limpa as circunvizinhanças dos locais de exploração e beneficiamento do mineral.

\subsection{Aplicações ornamentais e estruturais}

\subsubsection{Quartzito Ornamental}

O quartzito é uma rocha com várias qualidades estéticas, provindas de suas propriedades físico-químicas, cuja principal característica é a clivagem. No quartzito verifica-se planos preferenciais paralelos de quebra que permitem a obtenção de superfícies relativamente lisas e uniformes, se comparadas a outros materiais que necessitam de acabamentos como polimento, pois não se faz necessária essa técnica. Para obter objetos planos faz-se uso apenas de cunhas que direcionam forças perpendiculares em lugares salientes, retirando assim as imperfeições existentes.

A clivagem abre um leque de aplicações ornamentais para o quartzito porque é de extrema importância para a modelagem das peças a associação de coesão e boa trabalhabilidade, e como rocha metamórfica o quartzito tem essa coesão. Pode-se citar como exemplos a confecção de mesas e balcões, uso como piso de alta dureza e tenacidade, decoração de pilares e colunas, soleiras e tampos. O quartzito também pode ser utilizado em escadas, fachadas, praças, jardins, enfim em qualquer aplicação em que seja necessário um revestimento resistente. Além de todas essas aplicações feitas com o material trabalhado, ainda pode-se citar o emprego da rocha bruta e irregular como decoração.

O quartzito extraído na cidade de Várzea - PB é uma rocha de coloração predominantemente clara, geralmente branca em decorrência de seus minerais serem félsicos, podendo ter pigmentos escuros em função de minerais máficos ocorrentes do meio de formação. Isso Ihe permite ser aplicado na ornamentação também através de sua aplicação na indústria de 
tintas (pigmentação) e de vidro, devido à presença de quartzo. Observa-se ainda boa dureza, em torno de 7 na escala Moh, e seu traço também é de coloração clara. Contém ainda brilho natural em função da presença de micas e muscovitas na sua composição, cuja quantidade varia em cada formação rochosa.

\subsubsection{Quartzito Estrutural}

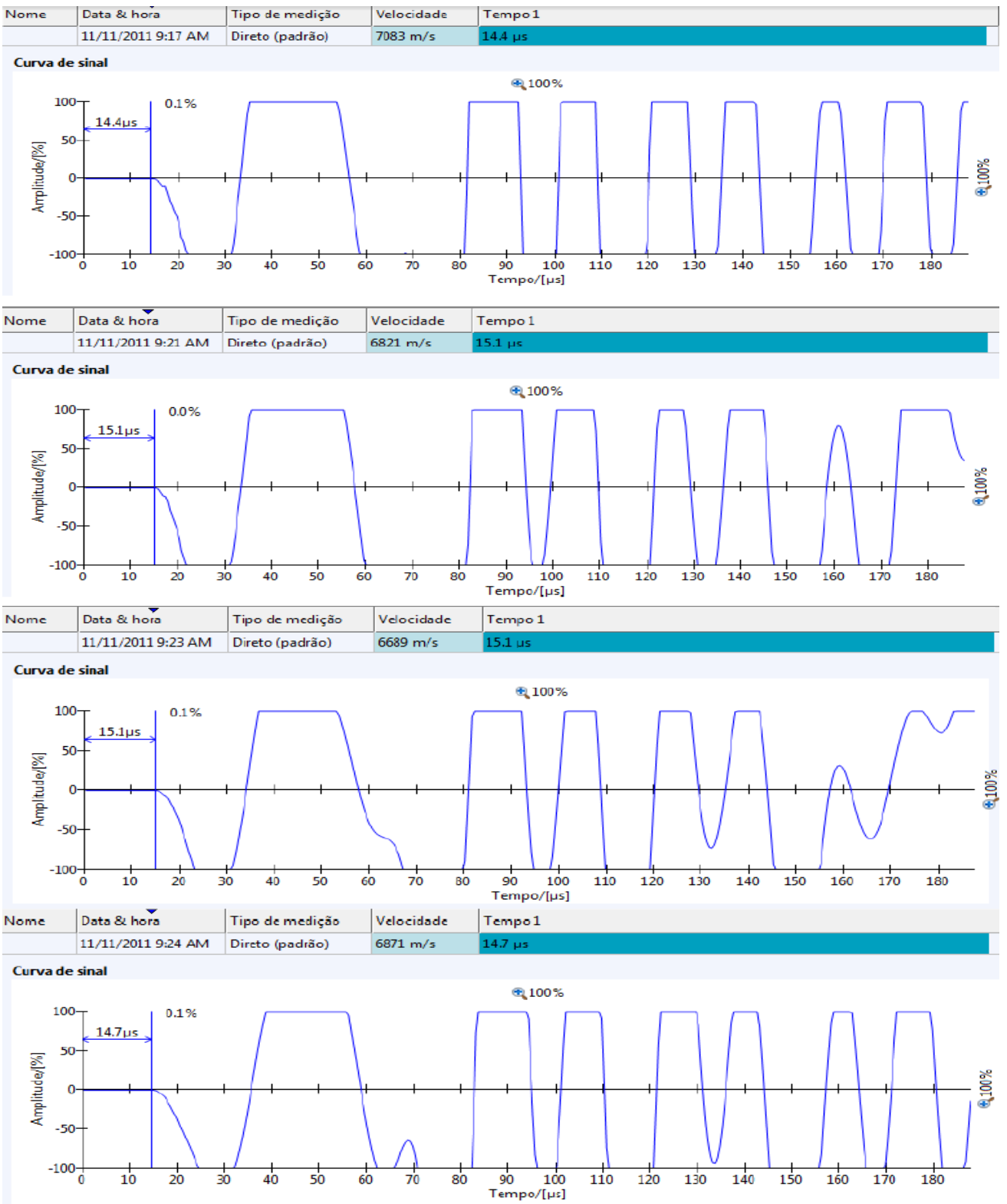

Figura 4: Análise de ondas ultrassônicas nos corpos-de-prova de quartzito de Várzea.

Na cidade de Várzea o quartzito já é utilizado para desempenhar funções estruturais (como aterros) devido à abundância do material. Mas essa realidade não existe, nem sequer é conhecida em grande parte das construções civis. O concreto é o material estrutural mais utilizado, seguido pelo aço (material com custo benefício mais elevado). O fato é que o quartzito é uma rocha metamórfica, isso já garante um bom arranjo tridimensional, coesão e densidade. É perfeitamente coerente levantar a hipótese de que o quartzito é tão resistente quanto o concreto, tendo em vista 
que o último é um produto de minerais decompostos de rochas e o quartzito é uma rocha natural bem consolidada.

Com o ensaio de ultrassom, foram averiguadas as velocidades de propagação de ondas no quartzito e no concreto. Nos gráficos da Figura 4, observa-se a análise feita nos corpos-de-prova de quartzito.

Esses gráficos indicam uma média de velocidade de $6866 \mathrm{~m} / \mathrm{s}$. A seguir os gráficos do software revelam as velocidades de propagação de ondas dos corpos-de-prova de concreto (Figura 5):

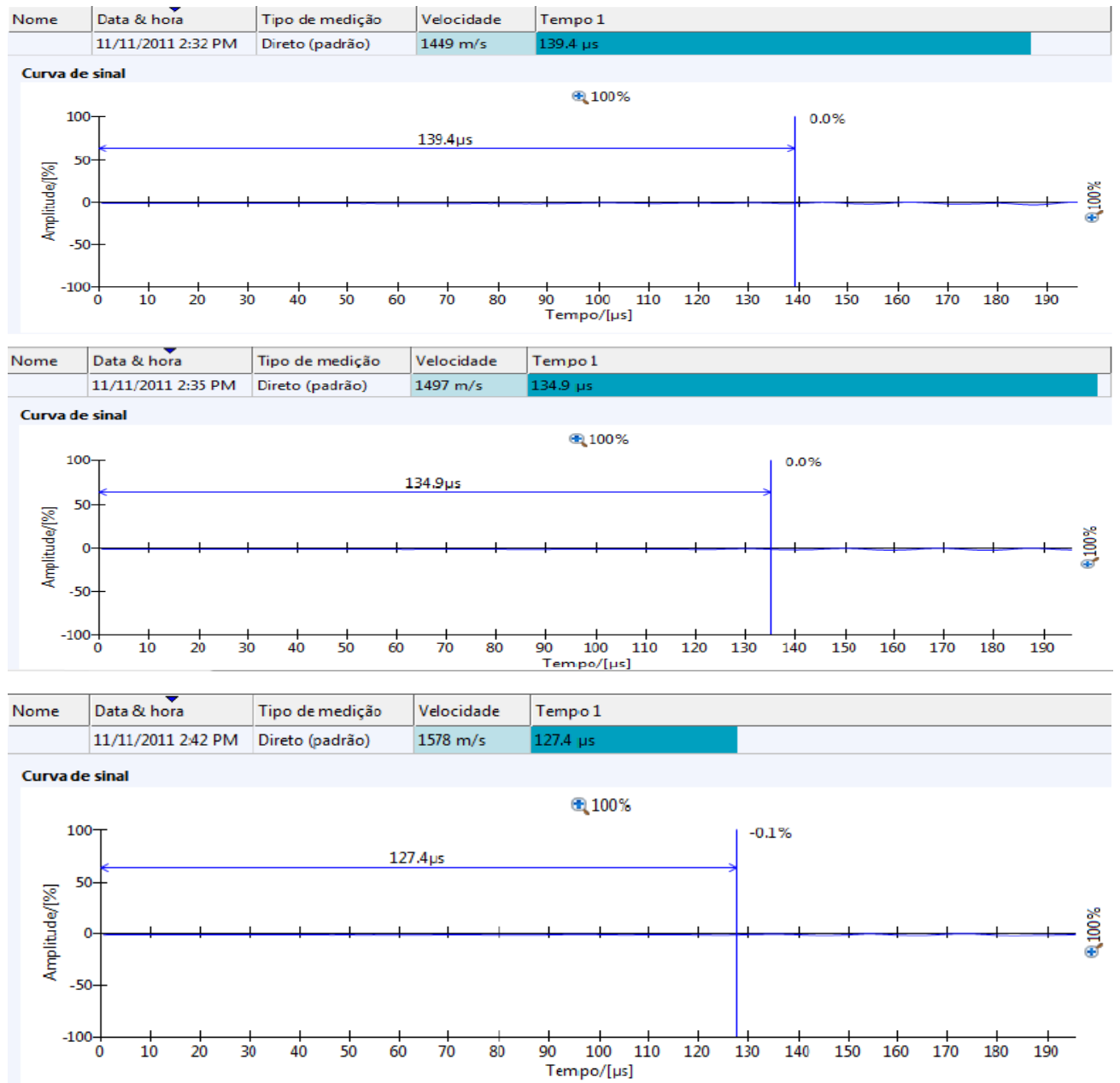

Figura 5: Análises de ultrassom nos corpos-de-prova de concreto fornecidos.

É possível observar uma média de velocidade de ondas para o concreto de $1508 \mathrm{~m} / \mathrm{s}$. Assim a velocidade de propagação de ondas do quartzito é 4,5 vezes maior que o concreto.

Através dos estudos pode-se afirmar que a resistência média para o concreto é de aproximadamente $34 \mathrm{MPa}$, para ensaios realizados aos 28 dias, enquanto a resistência do quartzito chega à $155 \mathrm{MPa}$. A resistência à compressão é diretamente relacionada com a densidade de um material e com seu índice de vazios, isto é, quando menor o índice de vazios e mais denso for um material, maior a sua resistência à compressão (BAUER, 2008). 
Vale salientar que existe uma correlação direta entre a velocidade de propagação de ondas ultrassônicas e as resistências à compressão uniaxial, ao módulo de ruptura e resistência à flexão na tração. Ou seja, quanto maior a velocidade de propagação maior a sua resistência, confirmando, dessa forma, a vantagem do quartzito sobre o concreto.

A relação expressa apenas uma estimativa da resistência do quartzito. No entanto, apesar de não serem considerados os diversos parâmetros, constata-se uma relação relevante, pois expressa um valor médio de resistência para os corpos-de-prova de quartzito dentro dos limites médios de resistência supracitados, entre 150 e $300 \mathrm{MPa}$, variando de acordo com a composição do quartzito (protólito e condições de formação).

Dentre os parâmetros que variam o valor real da resistência à compressão do quartzito vale salientar que, segundo Menezes \& Larizzatti (2005), o mesmo é composto de 70 a $95 \%$ de quartzo, mineral que possui resistência à compressão de $2 \mathrm{GPa}$, cerca de 10 vezes a resistência encontrada. Portanto é plenamente aceitável a resistência do quartzito estipulada, sendo quase 5 vezes mais resistente que o concreto. Além disso, a velocidade de propagação de $6866 \mathrm{~m} / \mathrm{s}$ está acima da média que é $6000 \mathrm{~m} / \mathrm{s}$, o que permite acreditar que a resistência do quartzito, se calculada através de seus parâmetros, seja bem maior do que a estimada nesse trabalho. De qualquer forma, a velocidade de propagação 4,5 vezes maior que o concreto reforça que o quartzito é mais resistente, como era de se esperar.

Dessa forma o quartzito é um material que pode ser utilizado em construção civil não apenas como rocha ornamental, mas também como rocha estrutural, podendo ser empregado como embasamentos, aterros e até mesmo como agregado para o concreto.

Por fim, comprova-se que o quartzito tem uma função estrutural proveniente de sua composição e arranjo interno. Esse fato despertou a curiosidade de pesquisa e hoje o quartzito também é utilizado para composição de argamassas, principalmente para os tipos de colagem de cerâmicas. É mais um leque aberto, já que, o quartzito pode ser utilizado triturado no lugar da areia (também para argamassas estruturais), até mesmo pelo grande teor de quartzo que ambos têm em comum, bem como a produção de tijolos.

\section{CONCLUSÕES}

As práticas extrativistas e de beneficiamento adotadas na cidade de Várzea - PB oferecem certo risco ao meio ambiente, gerando alteração do relevo devido à geração de resíduos sólidos.

O desmatamento também é presente, aumentando a possibilidade de desertificação, em longo prazo.

O consumo de água potável é o outro aspecto a ser observado, pondo em risco esse recurso escasso no semiárido.

Ornamentalmente, o quartzito é um excelente material, com boas propriedades físicas e estéticas, adequado para revestimentos externos e internos de edificações.

Do ponto de vista estrutural, verificou-se uma alta densidade e coesão no qurtizito, sendo mais consistente e resistente do que o concreto. 


\section{REFERÊNCIAS}

1. ASSOCIAÇÃO BRASILEIRA DE NORMAS TÉCNICAS. NBR 8802: Concreto endurecido Determinação da velocidade de propagação de onda ultra-sônica. Rio de Janeiro, 1994. 8p.

2. BAUER, F. L. A. Materiais de Construção. 5a ed. revisada. Rio de Janeiro: LTC, 2008. 471p.

3. BOTTEGA, F.; Análise do ensaio esclerométrico, um ensaio não destrutivo, nas estruturas de concreto - SC. Universidade do Extremo Sul Catarinense. Criciúma. Trabalho de Conclusão de Graduação em Engenharia Civil. 2010. 138 p.

4. FREITAS, E.; Extração mineral - Os impactos ambientais. 2009. Disponível em: $<$ http://mundoeducacao.uol.com.br/geografia/extracao-mineral-os-impactosambientais.htm>. Acesso em: 23 de agosto de 2011.

5. MENEZES, R. G.; LARIZZATTI, J. H. Rochas ornamentais e de revestimento: conceitos, tipos e caracterização tecnológica. Rio de Janeiro: UFRJ, 2005. 14p.

6. NEVES, C. A. R.; DA SILVA, L. R. Universo da Mineração Brasileira. Brasília: DNPM, 2007. 83p.

7. PARAHYBA, R. E. R.; CAVALCANTI, V. M. M.; PERLATTI, F. Mineração no Semiárido Brasileiro. Brasília: DNPM, 2009. 201p.

8. PETROBRÁS. N 1594: Ensaio não-destrutivo - ultrassom. Rio de Janeiro, 2004. 22p.

9. SOUZA, A. P. F., LIMA, A. A., GOPINATH, T. R., NADLER, H. C. S. Uma abordagem técnica e ambiental sobre os depósitos de quartzitos no estado da Paraíba. I Simpósio brasileiro de rochas ornamentais e II Seminário de rochas ornamentais do nordeste, Anais, realizado em Salvador, BA - 28 de novembro a 01 de dezembro de 2001. 


\section{ANEXOS}

\section{QUESTIONÁRIO DIRECIONADO AO CAMPO DE EXTRAÇÃO MINERAL}

1. Como é feita a extração mineral de quartzito na jazida?

( ) manualmente

( ) uso de explosivos

( ) outro tipo de recurso

2. Quais os impactos ambientais e os vestígios causados por essa exploração?

3. Qual a quantidade de resíduo sólido que a extração gera?

4. Quais os tipos de resíduos gerados e quais os graus de periculosidade?

5. É adotada a prática da reciclagem para o material não utilizado?

6. Quais os cuidados adotados para garantir a subsistência da jazida?

7. Existe algum estudo sobre a longevidade das mesmas para usufruto sadio?

8. Qual a capacidade estimada da jazida?

9. A retirada do material para o transporte é realizado de que forma?
( ) carroçamento
( ) uso de guincho
( ) outro tipo de recurso

10. O transporte até o local de beneficiamento é realizado de que forma?

( ) estratégia lógica de transporte coletivo

( ) individualidade de transporte

( ) outro meio de transporte

11. Qual a demanda e qual a extração média de quartzito?

12. Já foi detectada alguma alteração ambiental devido à exploração?

13. Os resíduos já ocasionaram algum efeito indesejado no ambiente?

14. Cite as aplicações conhecidas do quartzito.

15. Existe mais alguma informação relevante não contemplada?

\section{QUESTIONÁRIO DESTINADO ÀS INDÚSTRIAS DE BENEFICIAMENTO}

1. Como é feito o beneficiamento da matéria-prima (quartzito)?

2. Quais são os produtos finais obtidos nesse processo?

3. Quais os tipos de resíduos gerados na produção de cada um deles?

4. Qual a demanda e a quantidade usada de quartzito na produção?

5. O que é feito com o resíduo do processo de beneficiamento do quartzito?

6. Existe algum estudo mostrando possível aproveitamento desse material?

7. A prática de consciência ambiental é adotada?

8. O que é feito para amenizar compensando os danos à natureza?

9. Já foi detectada alguma alteração ambiental consequente do processo?

10. Cite as aplicações conhecidas do quartzito.

11. Existe mais alguma informação relevante não contemplada? 